\title{
DESIGN OF A CALCULATION FEM MODEL OF THE TEST STATIC SET-UP OF PIPE CONVEYOR FOR ANALYSIS OF CONTACT FORCES
}

\author{
Gabriel Fedorko', Vieroslav Molnár ${ }^{1}$ \\ 1 Technical University of Kosice, Letna 9, 04200 Kosice, Slovak Republic, e-mail: gabriel.fedorko@tuke.sk, \\ vieroslav.molnar@tuke.sk
}

Received: 2017.04.05

Accepted: 2017.05.10

Published: 2017.06.01

\begin{abstract}
Experimental research in the field of pipe conveyors is a difficult matter and yet necessary in order to answer the questions regarding the motion resistances and contact resistances of pipe conveyors, loading of the conveyor belts etc. These research activities can be performed not only during the actual operation of pipe conveyors, but also by means of the special laboratory test set-ups combined with the application of the computational simulation models. The main task of this paper is to assess the creation of a suitable simulation model of the test set-up for a specified pipe conveyor developed with regard to realisation of the FEM analyses, using the software product Abaqus, as well as presentation of its application possibilities.
\end{abstract}

Keywords: pipe conveyor, simulation, analysis, contact forces.

\section{INTRODUCTION}

Pipe conveyors belong to the group of continuous transport systems, which are increasingly popular in the systems of intra-plant logistics. Each final solution is original and although it is composed of the same construction parts as other pipe conveyors, the final form of the whole transport device is adapted to specific operating conditions and the place of installation.

The history of pipe conveyors goes back 70 years into the last century [2]. Their development and installation is also linked to the gradual development of the research in the field. The majority of initially realized research was aimed at improving the operational reliability and increasing performance, however, the research was not detailed. This trend of research in the field of pipe conveyors has been gradually attenuated, and at present particular researchers attempt to scrutinise detailed problems related to conveyor belt operation $[3,4]$.
This fact is more noted above all in recent years when the attention is focused on the research into the characteristics of conveyor belts, as found in Baburski [5], who studied in more detail the mechanical properties of rubber-textile conveyor belts. Others, who dealt with the research of pipe conveyors, Will and Staribacher [6], focused on the research of material conveying on long distances and also studied the characteristics and behaviour of conveyor belts.

Therefore, in recent years the research into the problem of pipe conveyors is focused predominantly on the conveyor belts and related operational characteristics. In terms of realization, it is a highly demanding problem, which focuses on measurements and experiments [7, 8]. Realization of experimental measurements during the normal operation of pipe conveyors is extremely demanding therefore most of experiments are conducted in laboratory conditions [9]. These experiments are focused on determining the strength properties of conveyor belts, as in Mazurkiewicz [10], or on the operational parameters of pipe conveyors [11, 12]. 


\section{DYNAMIC FRICTIONS OF THE PIPE CONVEYOR}

During the operation of pipe conveyors tasks are carried out and dynamic frictions are produced. Their creation is induced by mutual interaction of the endless conveyor belt and guide rollers. Broadly speaking, the study of dynamic frictions predominantly brings benefits in optimisation of cost for energy and lifetime of conveyor belts.

The value of dynamic frictions depends on the value of contact forces, which are the direct consequence of the already mentioned interaction between the conveyor belt and the guide roller. Therefore, it is necessary that the operator of pipe conveyors and their producers know the value of the contact forces and thus are able to set optimal operational conditions of the transport system to produce the most effective operation.

There are several ways to determine the size of dynamic frictions. The first method is the classic analytical calculation of the contact forces. The obtained results are greatly affected by the available data and material constants. Alternatively, the contact forces may be determined in experimental measurements in actual operational conditions. This way is relatively accurate however logistically demanding. The third method is presented by the form of realization of experimental measurement in laboratory conditions [13]. This measurement is not conducted in actual operational conditions but in simulated conditions, which are designed to imitate the actual ones. The important condition for the realization of this approach is the condition of disposal of s suitable test device. Finally, it should be noted that the second and third approach may be improved by means of computer simulation for example using FEM $[1,14]$.

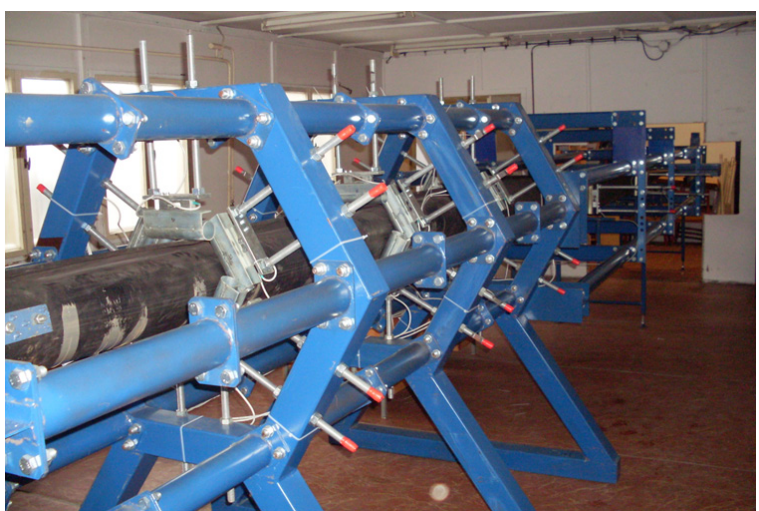

Fig. 1. Test set-up for measurement of contact forces of pipe conveyors



Fig. 2. Developed geometric model of the test set-up

\section{PIPE CONVEYOR TEST SET-UP}

There are several testing instruments for the measurement of contact forces of pipe conveyors around the world. These differ in design and measurement procedure. Figure 1 presents one of these testing devices.

This testing device consists of a set of three permanently joined hexagonal idler housings. Each idler housing is composed of six static guide rollers with measuring sensors. The test set-up enables measurements of different type rubber-textile conveyor belts for pipes of different diameters. After initial measurements it was resolved that simulation experiments and a more detailed FEM analysis was required. Therefore, it was necessary to create a mathematical model of this testing device $[15,16]$.

\section{FEM MODEL OF PIPE CONVEYOR STATIC TEST SET-UP}

The concept of the calculation model is based on its basic construction. The complex geometry of the FEM model was adapted to the custom design of the tested assembly: the conveyor belt surrounded by guide rollers.

The conveyor belt is located on guide rollers/ idlers, where the corresponding measuring sensors are located (Fig. 2). Other components of the test set-up were not represented in the model as they are not essential for the calculations. The process of calculation was divided into two steps, which were controlled by time curves.

In the first step, the model of the conveyor belt is located on the rolled out conveying rollers and it is loaded by its own weight. In the second step, by means of defined boundary conditions 


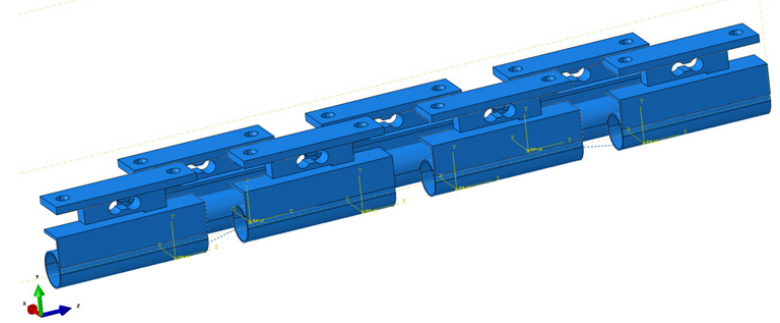

Fig. 3. Rollers with a local coordinate system

(Fig. 3), the gradual displacement of guide rollers to the required position was simulated. Simultaneously, the defined contact with individual rollers, allowed us to model the conveyor belt to gradually form the required shape.

Local coordinate systems were used for simulating the movement of rollers. Rollers were chain linked by kinematic connections. The rotation of rollers is shown in Table 1 . The boundary conditions were defined by the way that they allow only rotary motion. The middle roller No.4 has all degrees of freedom in the simulation model and its position does not change.

Seven rollers were used in the calculation model, even though the hexagonal idler housing is composed six rollers. This is dictated by the desired shape of the balled conveyor belt. Specifically, the process of balling at the second stage of calculation is divided into two parts, i.e. the rollers of the right half of rolled out model (Roller No.1, Roller No.2, Roller No.3) are rotated to the required shape. After its attainment, the left half starts to rotate (Roller No. 5, Roller No.6, Roller No.7). After roller No. 7 attains the required position, both edges of the conveyor belt are in contact which produces their overlap. Simultaneously, roller No. 1 loses the contact with the conveyor belt and its action force is transferred to the roller No.7 due to the contact with its sec-

Table 1. Defined displacement of rollers

\begin{tabular}{|c|c|c|c|}
\hline & \multicolumn{3}{|c|}{ Angular displacement [rad] } \\
\hline & $\begin{array}{c}\text { Idler housing } \\
\text { No.1 }\end{array}$ & $\begin{array}{c}\text { Idler housing } \\
\text { No.2 }\end{array}$ & $\begin{array}{c}\text { Idler housing } \\
\text { No.3 }\end{array}$ \\
\hline Roller No.1 & 3.14 & 3.14 & 3.14 \\
\hline Roller No.2 & 2.093 & 2.093 & 2.093 \\
\hline Roller No.3 & 1.046 & 1.046 & 1.046 \\
\hline Roller No.4 & 0 & 0 & 0 \\
\hline Roller No.5 & -1.046 & -1.046 & -1.046 \\
\hline Roller No.6 & -2.093 & -2.093 & -2.093 \\
\hline Roller No.7 & -3.14 & -3.14 & -3.14 \\
\hline
\end{tabular}

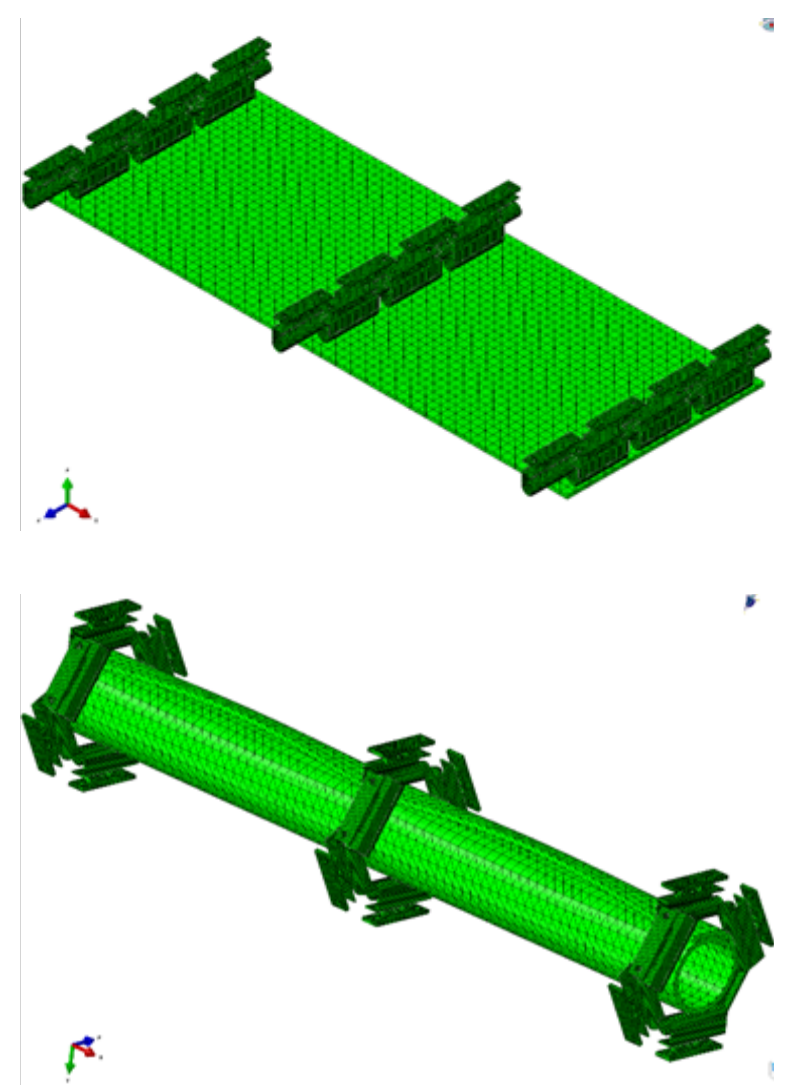

Fig. 4. Demonstration of the generated FEM model

ond edge. Rollers No.1 and 7 are not in contact and they are not affected by the model. The FEM network was created out of two types of elements (Fig. 4). The first type TET was used for the conveyor belt and the second type HEX was used for the guide rollers and pivoting members.

After shaping into a pipe, the model of conveyor belt is loaded by tension force in addition to its own weight. The value of the load depends on the type of modelled conveyor belt and operational conditions. The loading of the conveyor belt is defined at the right edge of the conveyor belt whereas the left edge is fixed. During the course of loading within the simulation the calculation is controlled by time curve which is defined in accordance with the realized experimental measurements (Fig. 5).

\section{THE APPLICATION OF THE MATHEMATICAL MODEL}

The presented mathematical model markedly expands the possibilities of experimental research into the dynamic frictions and contact forces of pipe conveyors. In the analysed field, it is of primary importance to establish the distribution of deformation zones along the whole surface of 


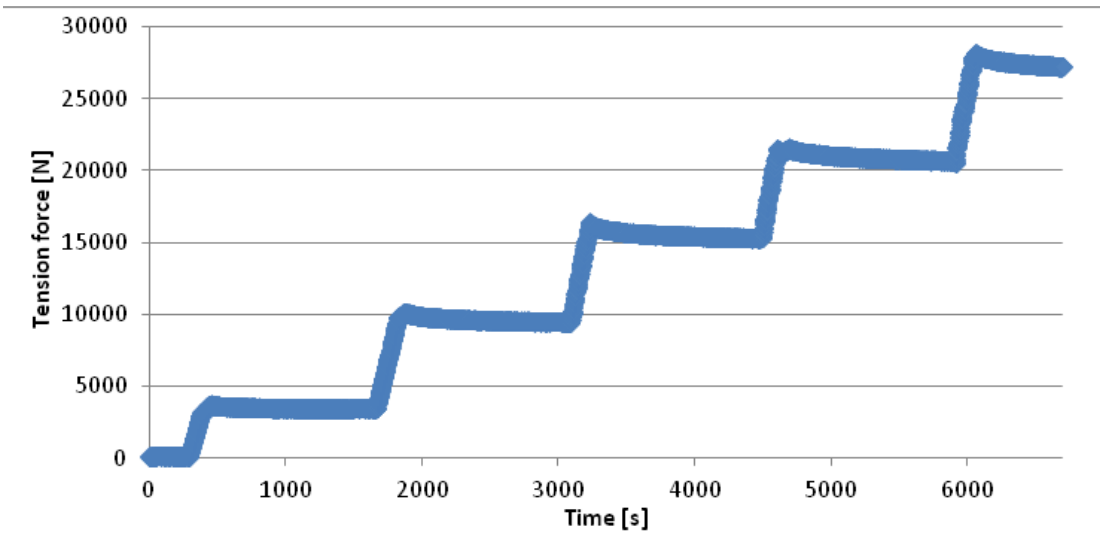

Fig. 5. Demonstration of the time curve for control of loading in tension

balled conveyor belt. This data cannot be obtained from experimental measurements.

Fig. 6 shows resulting deformation zones on the surface of the balled conveyor belt shaped into the pipe form. The results clearly indicate the position of deformation zones in the hexagonal idler housings. This highlights the size of the surface, which limits the range of contact forces effect and this affects the size of dynamic frictions. Also, it is possible to notice that the area of the belt which is not in contact with the guide rollers is only minimally affected by loading deformation forces.

A further observation shows the distribution of loading forces on the overlapping edges of the
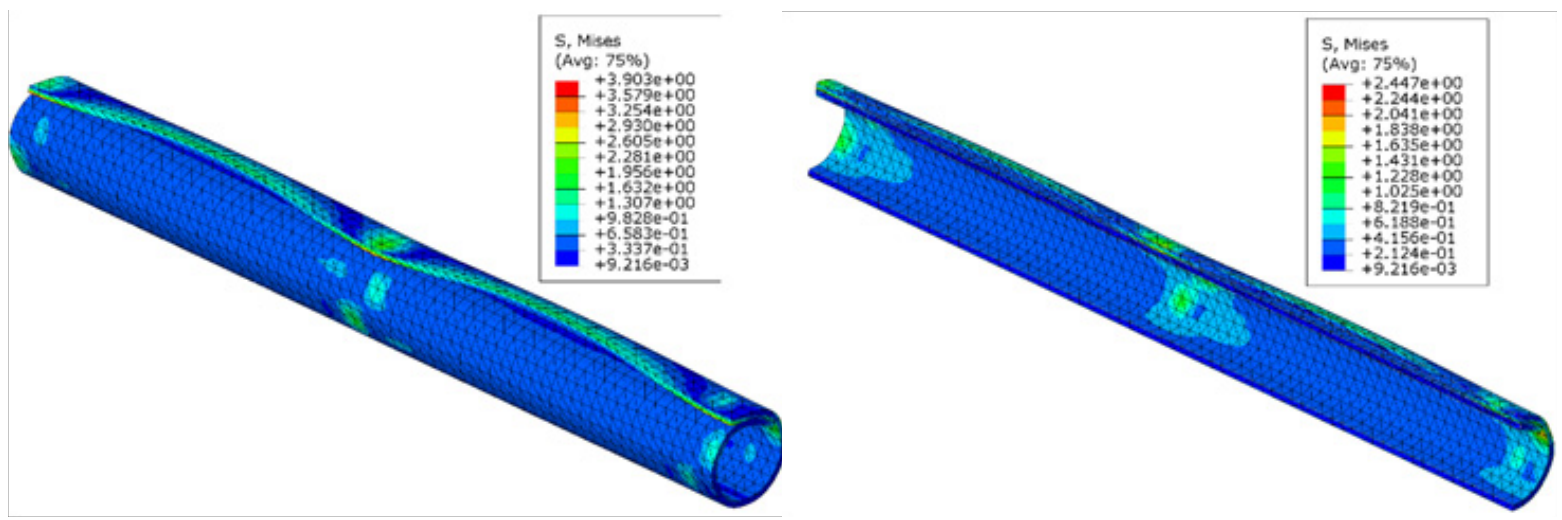

Fig. 6. Results of simulation

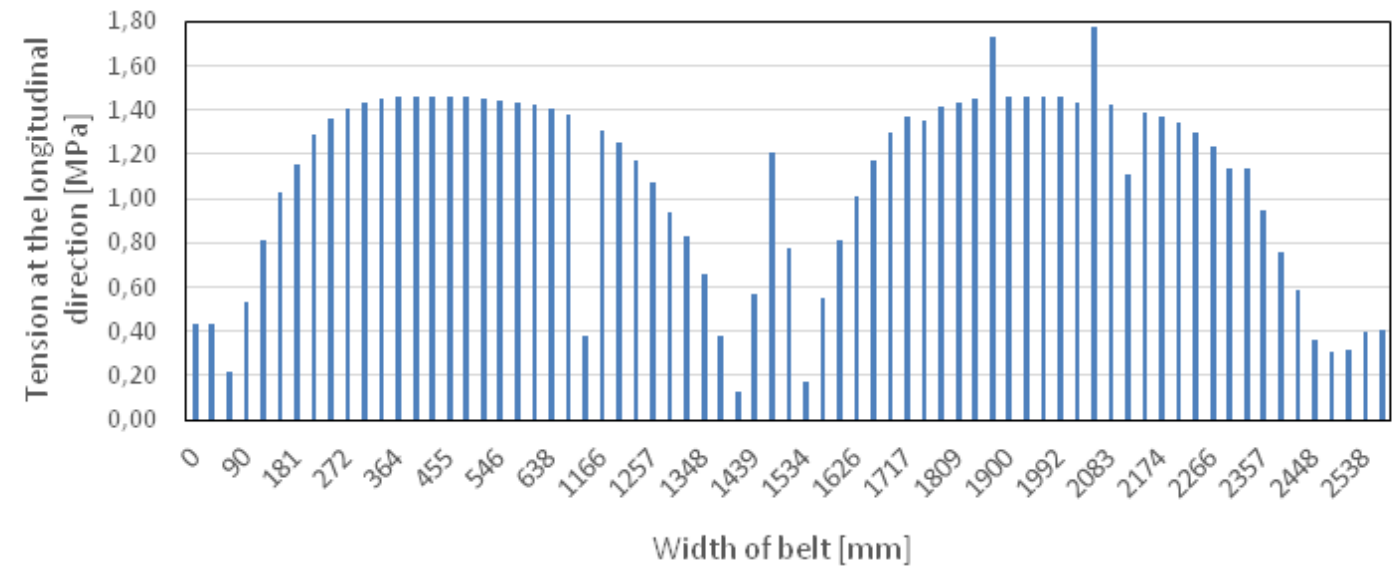

Fig. 7. Distribution of tension along the edges of the conveyor belt 

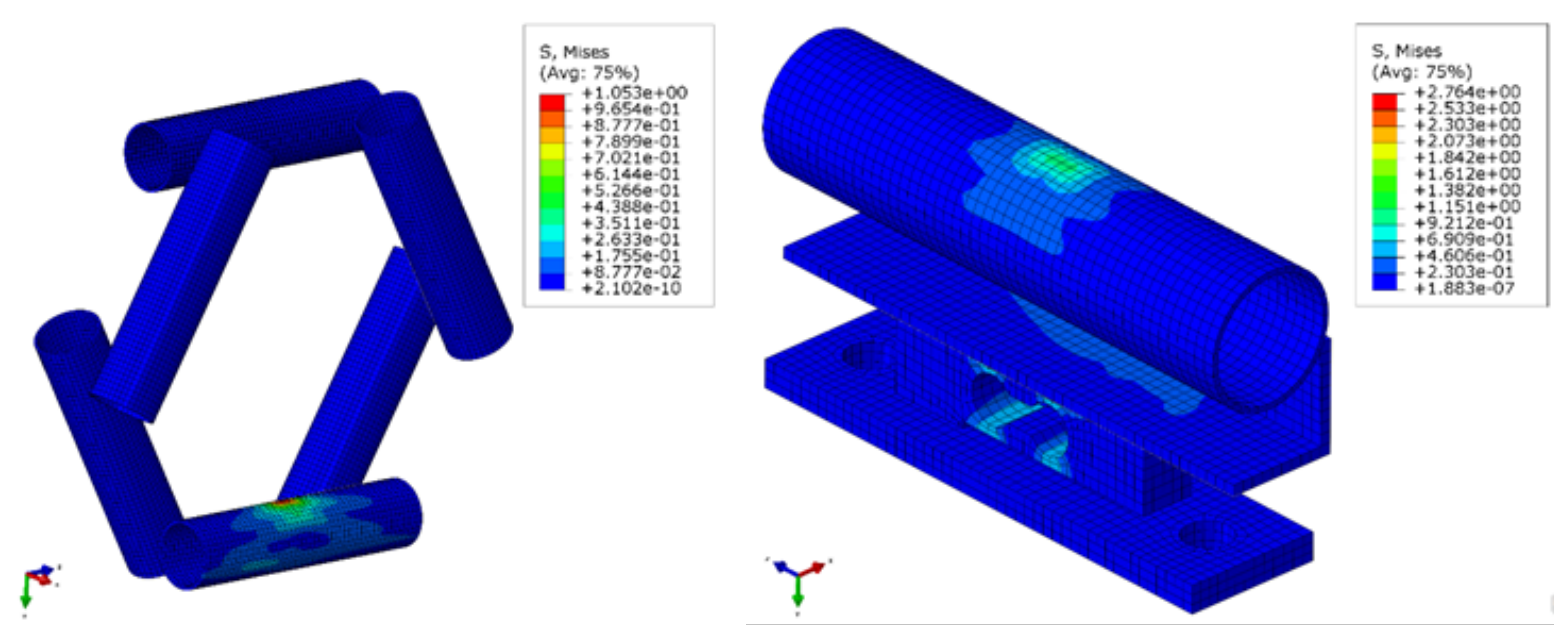

Fig. 8. Distribution of tension on the surface of guide rollers
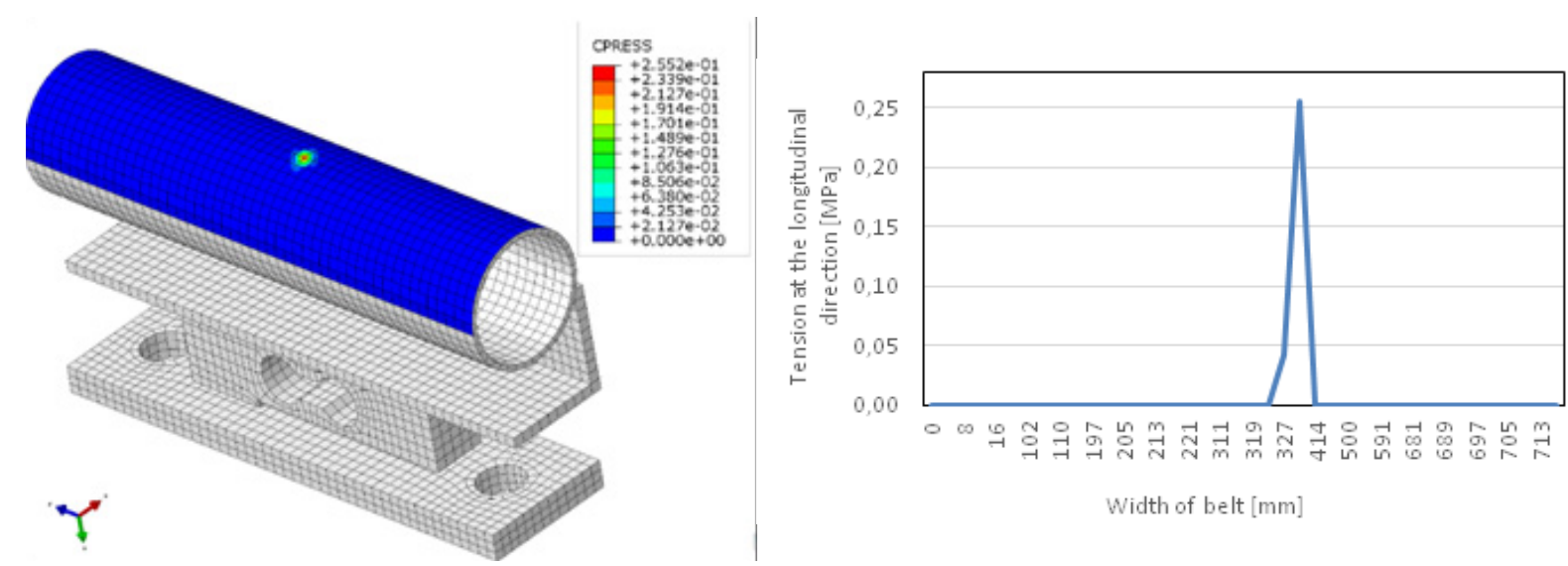

Fig. 9. Values of contact force on the surface of guide rollers

balled conveyor belt, which is presented is presented in Figure 7.

The map of tension distribution, allows us to predict the size of mutual friction of the edges of the conveyor belt and the resulting wear. Another interesting fact is the loading of guide rollers by pressure of balled conveyor belt. The visualization of the value, position and range of actions is presented in Fig. 8. The gathered information indicates whether the type of conveyor belt used in tests is not too soft or too hard. Both of these states significantly affect the amount of dynamic frictions and thus affect the operating characteristics of pipe conveyor as well as the amount of wear.

The mathematical model also allows us to assess the forming rollers regarding the values of contact force (Fig. 9). Fig. 9 shows the place where the contact between the balled conveyor belt and guide roller occurs. The result of the calculation clearly presents the surface which creates the contact. This helps to assess whether the conveyor belt is well-positioned in the hexagonal idler rollers. The analysis may also help to prevent contact in undesirable places, for example edges of guide rollers, etc.

\section{CONCLUSIONS}

Researching dynamic frictions of pipe conveyors is highly complicated to realize without realization of experimental measurements. Although the data obtained in this way is important and necessary, it is often insufficient if they not supported by other analyses by means of simulation experiments. The development of an adequate simulation model is far from easy and demands great skills in computer simulation and handling of simulation software.

The combination of data obtained from experimental measurements and simulation calculations is nowadays the key to the research of 
dynamic friction of pipe conveyors and, furthermore, any advance in the field would be impossible without their effective application.

\section{Acknowledgements}

This work is a part of the following projects VEGA 1/0063/16, KEGA 014STU-4/2015, KEGA 018TUKE-4/2016.

\section{REFERENCES}

1. ABAQUS/Explicit,Version 6.9-1. Simulia documentation for the Abaqus Unified FEA product suite. T. , Providence, 2009.

2. Imai A. Pipe Conveyor Development, Benchmark and Future Trend. Bulk Solids Handling, 20(2), 2015.

3. Rozbroj J., Zegzulka J., Nečas J. Use of DEM in the Determination of Friction Parameters on a Physical Comparative Model of a Vertical Screw Conveyor. Chem. Biochem. Eng. Q., 29, 2015, 25-34.

4. Honus, S., Bocko, P., Bouda, T., Ristović, I., Vulić, M.: The effect of the number of conveyor belt carrying idlers on the failure of an impact place: A failure analysis. Eng. Fail. Anal., 77, 2017, 93-101.

5. Barburski M. Analysis of the mechanical properties of conveyor belts on the three main stages of production. Journal of Industrial Textiles, 45(6), 2014, 1-13.

6. Will F., Staribacher J. Pipe conveyors transport bulk material efficiently over long distances. Rohrgurtförderer Transp. Schüttgut effizient über lange Strecken, 63, 2011, 146-155.

7. Gajdos I., Slota J., Spisak E., Jachowicz T., TorSwiatek A. Structure and tensile properties evaluation of samples produced by Fused Deposition Modeling. Open Eng., 6, 2016, 86-89.
8. Michalik P., Zajac J. Using of computer integrated system for static tests of pipe conveyer belts. In: 13th Int. Carpathian Control Conf. (ICCC). High Tatras. pp. 480-485, 2012.

9. Zamiralova M.E., Lodewijks G. Measurement of a pipe belt conveyor contact forces and cross section deformation by means of the six-point pipe belt stiffness testing device. Measurement, 70, 2015, 232-246.

10. Mazurkiewicz D. Problems of identification of strength properties of rubber materials for purposes of numerical analysis : a review. Arch. Civ. Mech. Eng., 10(1), 2010, 69-84.

11. Egorov A.P. Definition of longitudinal critical speed size at vertical fluctuations of a tubular conveyor's belt. Mining Informational Anal. Bull., 2009, 138-143.

12. Husáková N., Honus S. Reverse Material Flow of Worn-Out Conveyor Belts. Appl. Mech. Mater., 683, 2014, 183-188.

13. Madáč K., Durkáč V., Král' J. Design of applications for CAD system Creo Parametric 1.0. Int. Sci. Her., 4, 2012, 278-284.

14. Strohmandl J. Use of simulation to reduction of faulty products. UPB Sci. Bull. Ser. D Mech. Eng., 76, 2014, 223-230.

15. Mantič M., Kul'ka J., Krajňák J., Kopas M., Schneider M. Influence of selected digitization methods on final accuracy of 3D model. In: Majerník, M., Daneshjo, N., and Bosák, M. (eds.) Production Management and Engineering Sciences. pp. 475-480. CRC Press Taylor and Francis Group A Balkema Book, 2016.

16. Debski H., Koszalka G., Ferdynus M. Application of FEM in the analysis of the structure of a trailer supporting frame with variable operation parameters. Eksploatacja i Niezawodnosc-Maintenance and Reliability, 14, 2012, 107-113. 